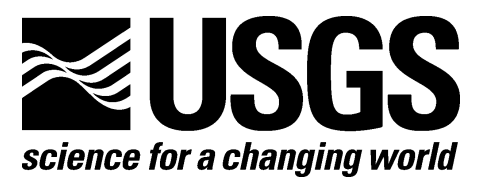

In cooperation with the U.S. Department of Energy, National Nuclear Security Administration Nevada Site Office

\title{
Electrical Resistivity and Seismic Surveys at the Nevada Test Site, Nevada, April 2007
}

By Seth S. Haines, Bethany L. Burton, Donald S. Sweetkind, and Theodore H. Asch

Open-File Report 2008-1368

U.S. Department of the Interior

U.S. Geological Survey 


\section{U.S. Department of the Interior DIRK KEMPTHORNE, Secretary}

\section{U.S. Geological Survey \\ Mark D. Myers, Director}

U.S. Geological Survey, Reston, Virginia 2008

Prepared in cooperation with the U.S. Department of Energy, National Nuclear Security Administration Nevada Site Office under Interagency Agreement, DE-AI52-07NA28100

For product and ordering information:

World Wide Web: http://www.usgs.gov/pubprod

Telephone: 1-888-ASK-USGS

For more information on the USGS - the Federal source for science about the Earth, its natural and living resources, natural hazards, and the environment: World Wide Web: http://www.usgs.gov

Telephone: 1-888-ASK-USGS

Suggested citation:

Haines, S. S., Burton, B. L., Sweetkind, D. S., Asch, T. H., 2008, Electrical Resistivity and Seismic Surveys at the Nevada Test Site, Nevada, April 2007, U.S. Geological Survey Open-File Report 2008-1368, 33 p.

Any use of trade, product, or firm names is for descriptive purposes only and does not imply endorsement by the U.S. Government.

Although this report is in the public domain, permission must be secured from the individual copyright owners to reproduce any copyrighted material contained within this report. 


\section{Contents}

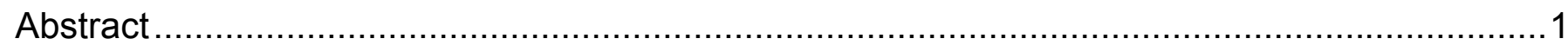

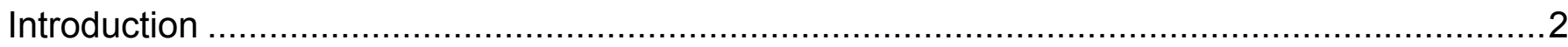

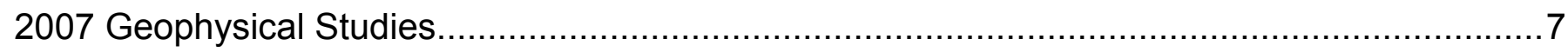

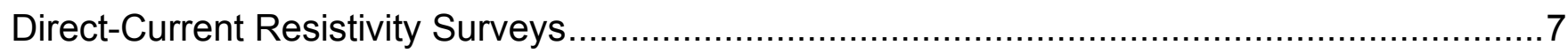

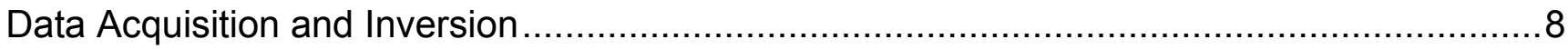

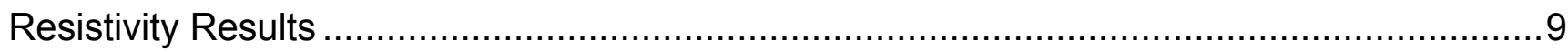

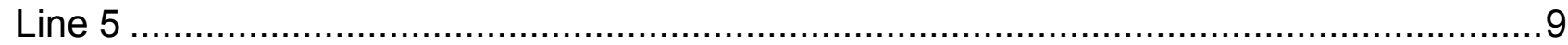

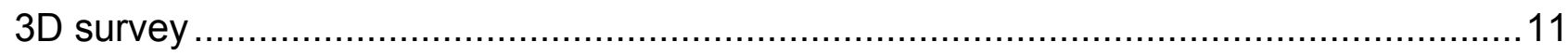

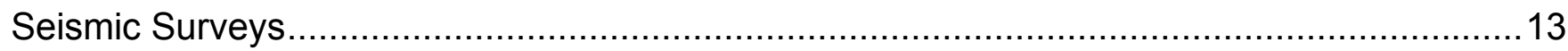

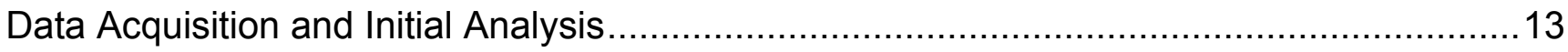

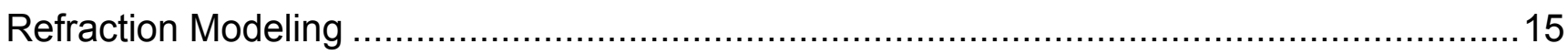

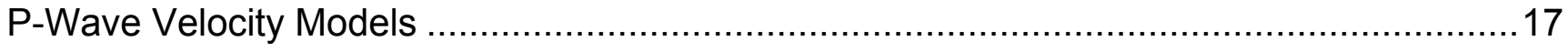

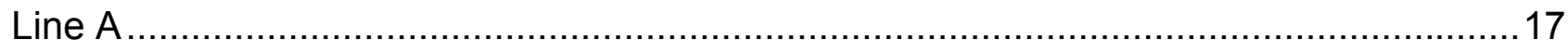

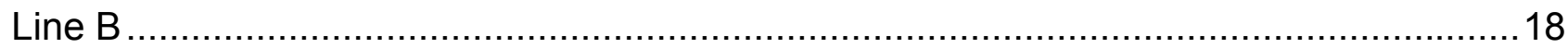

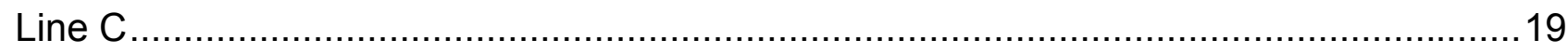

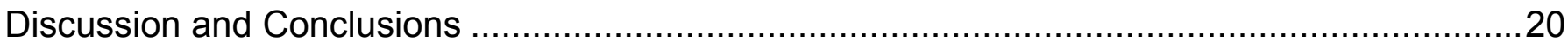

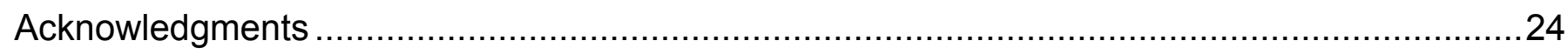

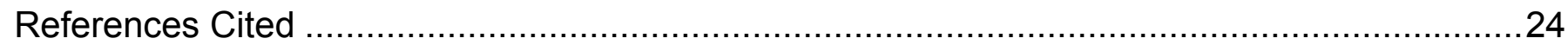

Appendix A

Appendix B 


\title{
Electrical Resistivity and Seismic Surveys at the Nevada Test Site, Nevada, April 2007
}

\author{
By Seth S. Haines, Bethany L. Burton, Donald S. Sweetkind, and Theodore H. Asch
}

\section{Abstract}

In April 2007, the USGS collected direct-current (DC) electrical resistivity data and shear- (S) and compressional- (P) wave seismic data to provide new detail of previously mapped, overlapping fault splays at two administrative areas in the Nevada Test Site (NTS). In NTS Area 7, we collected twodimensional DC resistivity data along a transect crossing the Yucca Fault parallel to, and between, two transects along which resistivity data were collected in a previous study in 2006. In addition, we collected three-dimensional DC resistivity data in a grid that overlies part of the 2007 transect. The DC resistivity data show that the fault has a footwall that is more conductive than the hanging wall and an along-strike progression of the fault in a location where overlapping splays are present. Co-located with the northernmost of the two 2006 DC resistivity transects, we acquired S- and P-wave seismic data for both reflection and refraction processing. The S-wave data are corrupted by large amounts of converted (P-wave) energy likely due to the abundance of fractured caliche in the shallow subsurface. The P-wave data show minimal reflected energy, but they show clear refracted first arrivals. We have inverted these first arrival times to determine P-wave seismic velocity models. The seismic model for the transect in Area 7 shows low velocities extending to the base of the model at the location of the Yucca Fault, as well as low velocities at the eastern end of the transect, in the vicinity of the adjacent crater. These new surveys provide further detail about the geometry of the Yucca Fault in this location where it shows two overlapping splays.

We collected P- and S-wave seismic data along a transect in the southern part of NTS Area 2, corresponding with the location of a 2006 DC resistivity transect that targeted a set of small faults identified with field mapping. Again, the S-wave data are difficult to interpret. The P-wave data show 
clear first arrivals that we inverted, yielding a velocity model that shows lateral heterogeneity similar to the 2006 DC resistivity models. Finally, we collected P-wave data along a second transect in Area 2, located north of the first line and in an area of a very minor fault that was targeted by another 2006 DC resistivity survey. The P-wave refraction velocity model shows generally high velocities, with a zone of somewhat lower velocities in the central part of the transect. The position of the low velocity zone corresponds with the location of a minor fault, though it is unclear whether the two are related.

Together, these results demonstrate the value of geophysical data for mapping the subsurface extent of faults. The 2007 DC resistivity data complement the 2006 data and provide important new detail of the overlapping fault splays. The seismic data demonstrate the ability of P-wave refraction methods to identify the damage zones at faults, and they show the difficulties associated with S-wave methods in areas with caliche. Combining all of the geophysical data from the Area 7 studies, we are able to develop a coherent interpretation of the relation between the site geology, the fault, and the observations.

\section{Introduction}

The subsurface geology of Yucca Flat, an elongated basin within the Nevada Test Site and the greater Basin and Range Province, consists of alluvial deposits overlying Miocene volcanic rocks and Paleozoic carbonate bedrock (Slate and others, 2000). At the surface, alluvial materials are partially cemented by caliche throughout the study area. The Yucca Fault is a north-striking, east-dipping, normal fault located in the eastern half of Yucca Flat (fig. 1), and it shows a meter-scale surface scarp and bedrock offsets of 200-400 m. Yucca Fault has distinct splays and step-overs in some locations, and it is also accompanied by many other smaller faults throughout the area (Grasso, 2001). In many cases, these smaller faults are anthropomorphic in nature, having been created by the testing of nuclear weapons at the site (see, for example, Barosh, 1968). Together, these faults play an important role in controlling ground-water flow and transport at the Nevada Test Site (Winograd and Thordarson, 1975). 


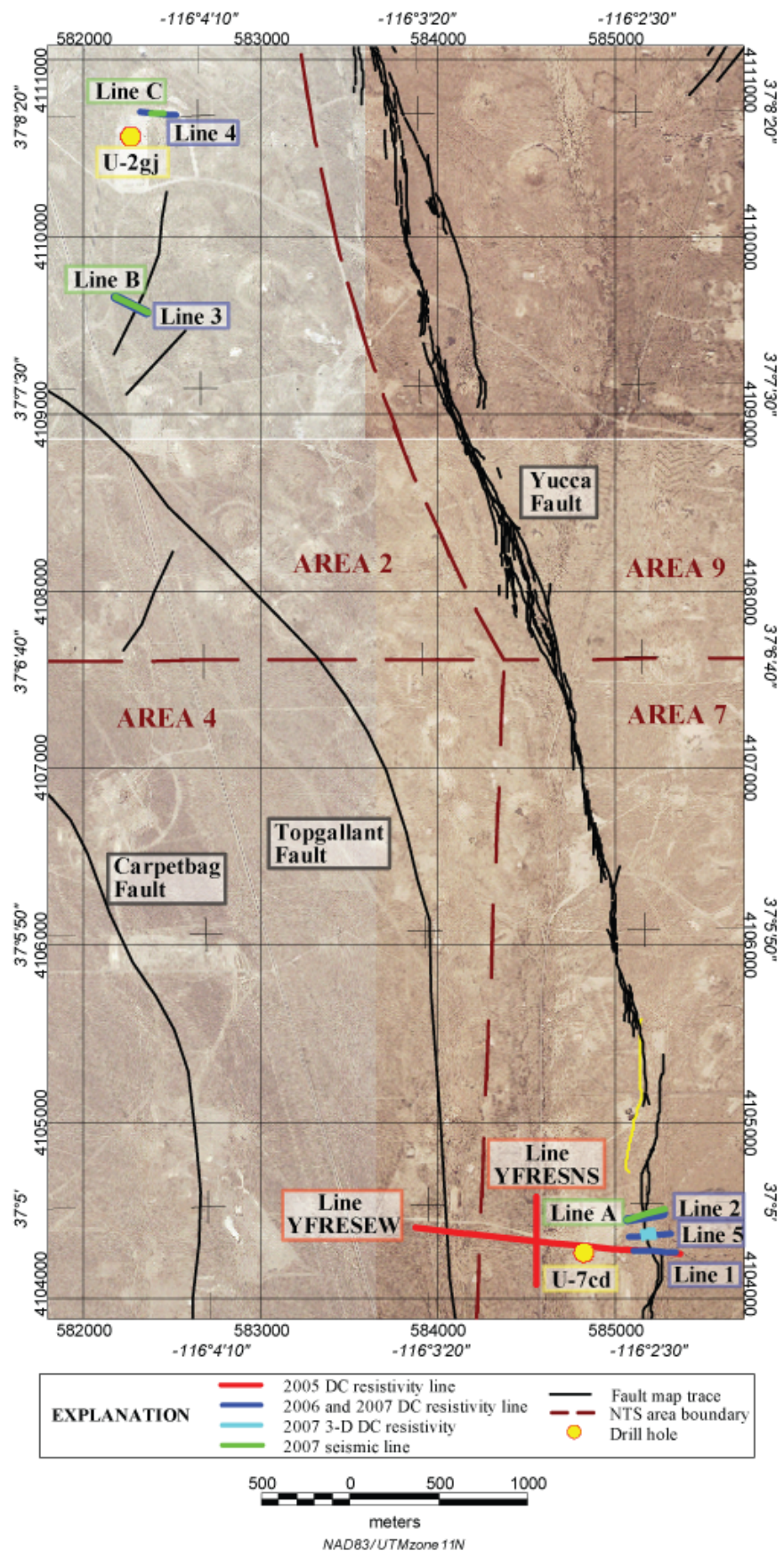

Figure 1. Aerial photograph of the geophysical study areas in Areas 2 and 7 in Yucca Flat of the Nevada Test Site with the locations of the DC resistivity and seismic surveys shown. For each survey transect, the color of the label box matches the color of the line shown on the map. The major mapped fault traces are overlaid (Yucca Fault from Slate and others (2000); other faults and surface cracks are from Grasso (2001)). One strand of the Yucca Fault is plotted in yellow in order to identify it for later discussions. U-2gj and U-7cd are emplacement boreholes, included in the figure for reference. 
The USGS and other groups have conducted numerous studies to determine the geometry and physical properties of these faults (for example, Asch and others, 2006; Phelps and McKee, 1999). Asch and others (2008) present audio magnetotelluric, direct-current (DC) electrical resistivity, and total field magnetic data collected in Areas 2 and 7 of the Nevada Test Site in 2005 and 2006. In Area 7, two west-east trending DC resistivity transects were acquired in 2006 and cross the Yucca Fault approximately $200 \mathrm{~m}$ from each other (Lines 1 and 2 in figs. 1 and 2). Inversion results show a distinct along-strike (south-to-north) progression as the fault steps to the west in a location with overlapping splays. The DC resistivity models show the fault separating a footwall zone of low resistivity (high conductivity) from a hanging wall zone of higher resistivity (lower conductivity). This electrical contrast corresponds with the location of a strong lateral total field magnetic gradient that is also present at the fault (Asch and others, 2008).

In Area 2, Asch and others (2008) describe two west-east DC resistivity transects that cross smaller mapped faults. The model for the southernmost transect (Line 3 in figs. 1 and 3) shows zones of relatively high and low resistivity that appear to be separated by the downward extension of mapped surface cracks or faults discussed by Grasso (2001). The northern Line 4 shows little variation across a very small fault that was identified in an excavated trench. 


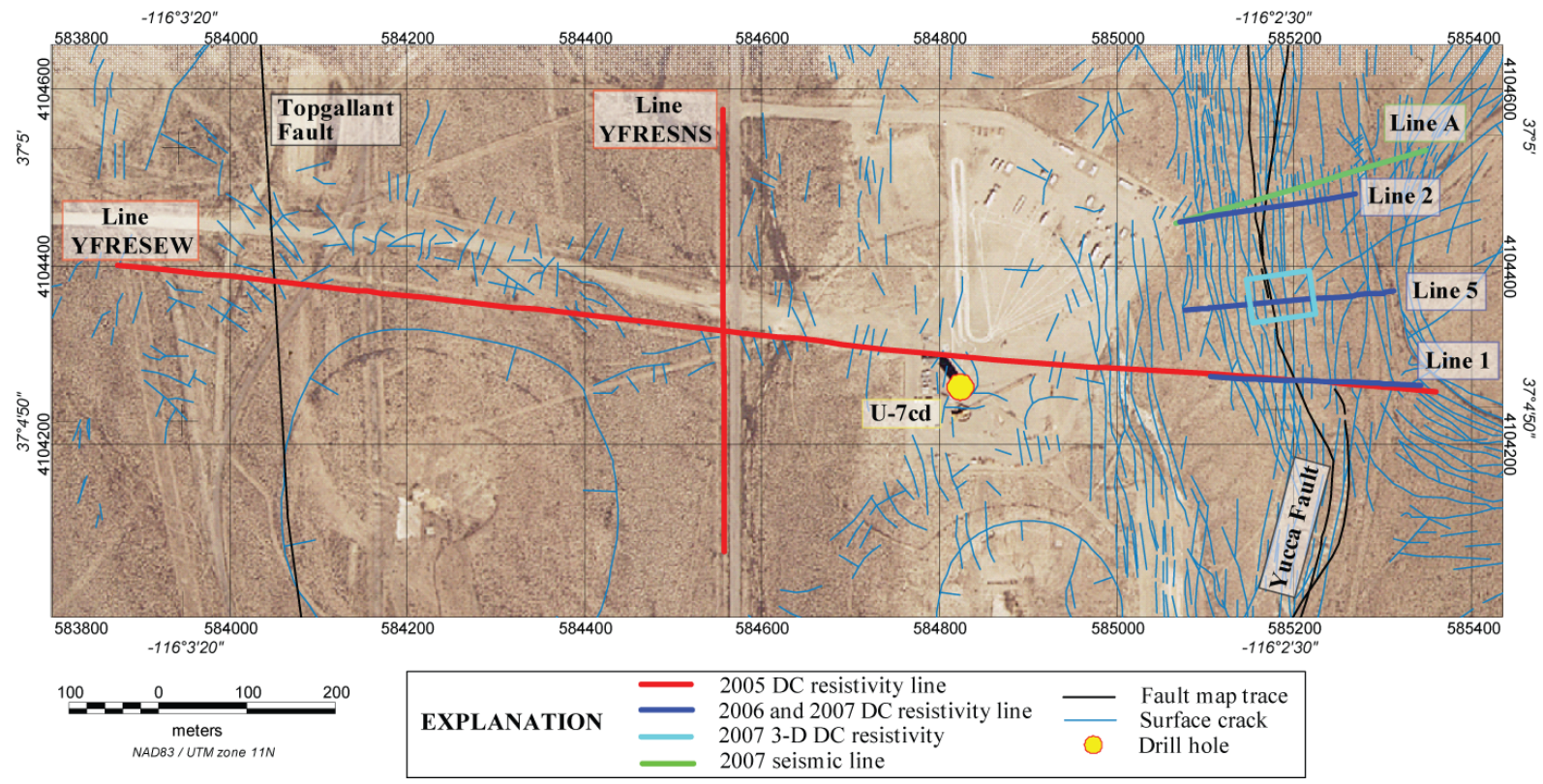

Figure 2. Map of the Area 7 seismic and DC resistivity surveys with the mapped fault traces (Slate and others, 2000) and surface cracks (Grasso, 2001) overlaid. 


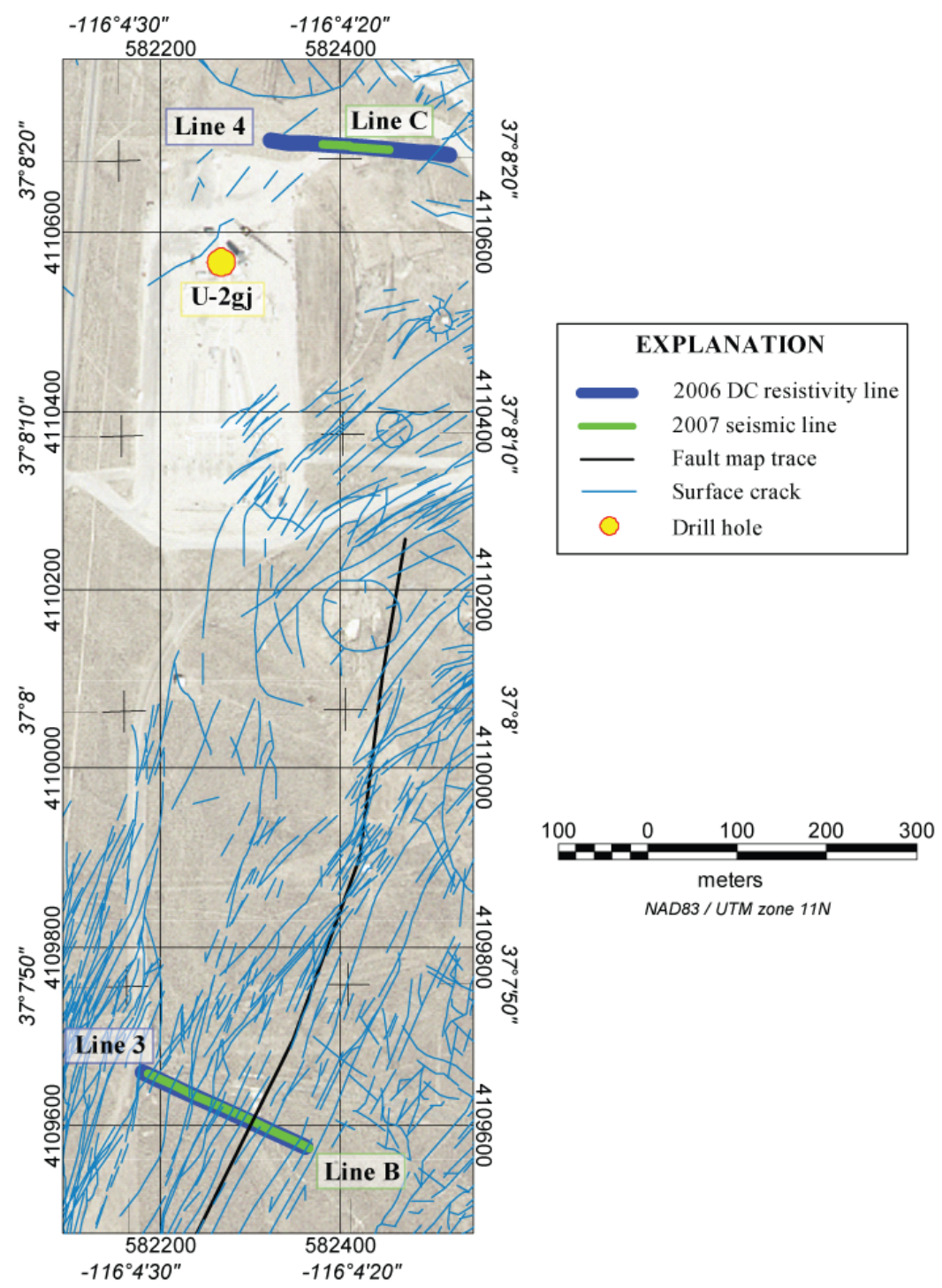

Figure 3. Map of the Area 2 seismic and DC resistivity surveys with the mapped fault traces (Slate and others, 2000) and surface cracks (Grasso, 2001) overlaid.

In April 2007, we conducted seismic and DC resistivity surveys in Areas 7 and 2 in order to further constrain the geometry and physical properties of the previously studied faults. We collected DC resistivity data along Line 5 midway between Lines 1 and 2 (fig. 2). In addition, we collected threedimensional (3D) DC resistivity data using an electrode grid roughly centered on Line 5. In Area 7 we collected compressional- $(\mathrm{P})$ and shear- $(\mathrm{S})$ wave seismic data along a transect very near and subparallel 
to DC resistivity Line 2. In Area 2, we collected P- and S-wave seismic data along DC resistivity Line 3, and we collected P-wave data along DC resistivity Line 4.

In this report, we present the 2007 geophysical data. First, we describe the new DC resistivity surveys and compare them with previous surveys. Then, we present and discuss the seismic data and show P-wave refraction velocity models for each transect. Finally, we discuss our data, in the context of previously published results, in order to develop a coherent understanding of the faults and their physical properties.

\section{Geophysical Studies}

We used a real-time kinematic (RTK) Leica GPS1200 global positioning system (GPS) to determine high-precision locations for the 2007 DC resistivity and seismic profiles. All horizontal coordinates are referenced to the North American Datum 1983 (NAD83). All elevations are referenced to the North American Vertical Datum 1988 (NAVD 88). Depth refers to depth below the ground surface.

\section{Direct-Current Resistivity Surveys}

The direct-current resistivity method is used to determine the electrical resistivity structure of the subsurface. Resistivity is defined as a measure of the opposition to the flow of electric current in a material. The resistivity of a soil or rock is dependent on several factors that include amount of interconnected pore water; porosity; amount of total dissolved solids (TDS), including salts, in the pore water; and mineral composition (especially mineralogical clays). The DC resistivity method is

described by Zohdy and others (1974), Sumner (1976), Reynolds (1997), and Rubin and Hubbard (2006). 


\section{Data Acquisition and Inversion}

The results of our detailed DC resistivity study across Yucca Fault in Area 7 in 2006 led us to conduct a 3D survey in the same area. First, we acquired data along a third transect (Line 5) between the two surveyed in 2006 (Lines 1 and 2) in order to better place the electrode grid. We used the same survey design for Line 5 that we used for Lines 1 and 2 so that we could directly compare all transects (table 1). Each layout included 100 electrodes with one roll-along, or move, of 20 electrodes from the beginning of the spread to the end to extend the line. The SuperSting R8/IP, manufactured by Advanced Geoscience Inc., was used for all of the USGS DC resistivity surveys at the Nevada Test Site. Appendix A contains the raw-data and forward-modeled pseudosections for all three DC resistivity transects.

Table 1. Summary of $D C$ resistivity acquisition parameters for $2 D$ transects acquired across Yucca Fault in Area 7 in 2006 and 2007.

\begin{tabular}{|c|c|c|c|}
\hline Line & $\mathbf{1}$ & $\mathbf{2}$ & $\mathbf{5}$ \\
\hline \hline Number of Electrodes & 120 & 100 & 120 \\
\hline Electrode Spacing & \multicolumn{3}{|c|}{$2 \mathrm{~m}$} \\
\hline Line Length & $238 \mathrm{~m}$ & $198 \mathrm{~m}$ & $238 \mathrm{~m}$ \\
\hline Measurement Time & \multicolumn{3}{|c|}{$800 \mathrm{~ms}$} \\
\hline Array Type & \multicolumn{3}{|c|}{ Inverse Schlumberger } \\
\hline
\end{tabular}

Based on the profile results and the spatially varying character of the surface scarp, we placed the resistivity grid roughly centered over Line 5. In the area of the grid, the surface scarp bulges slightly toward the east and contains an eroded drainage feature. We used a square grid of 100 electrodes with equal in-line electrode and line spacing of $5.5 \mathrm{~m}$ (table 2). We rolled along twice to extend the data coverage well beyond the surface scarp. Each roll-along moved two rows of 10 electrodes each from the beginning of the grid (west side) to the end (east side). We used a radial dipole-dipole array for this $3 \mathrm{D}$ dataset. Although the electrode spacing of $5.5 \mathrm{~m}$ for the grid is greater than the $2 \mathrm{~m}$ spacing used for the transects, the depth of penetration of the 3D survey is greatly reduced because the maximum 
separation of the current and potential electrodes is smaller. We used an electrode spacing of $5.5 \mathrm{~m}$ because this is the maximum practical spacing that is allowed by our multi-electrode cables, and we wanted to maximize the coverage and investigation depth of the survey given our time and budget constraints.

Table 2. Summary of DC resistivity acquisition parameters for the 3D grid acquired across Yucca Fault in Area 7 in 2007.

\begin{tabular}{|c|c|c|c|c|c|}
\hline Geometry & $\begin{array}{c}\text { Total Num. } \\
\text { Electrodes }\end{array}$ & $\begin{array}{c}\text { Inline } \\
\text { Electrode } \\
\text { Spacing }\end{array}$ & $\begin{array}{c}\text { Line } \\
\text { Spacing }\end{array}$ & $\begin{array}{c}\text { Total Grid Size } \\
\text { [Electrodes] }\end{array}$ & Array Type \\
\hline \hline rectangular grid & 140 & $5.5 \mathrm{~m}$ & $5.5 \mathrm{~m}$ & $\begin{array}{c}49.5 \times 71.5 \mathrm{~m} \\
{[10 \mathrm{~N} \times 14 \mathrm{E}]}\end{array}$ & $\begin{array}{c}\text { radial } \\
\text { dipole-dipole }\end{array}$ \\
\hline
\end{tabular}

We applied topographic corrections and inverted the Line 5 data with the same modeling parameters as the 2005 and 2006 DC resistivity data (Asch and others, 2008) using EarthImager 2D (AGI, 2007a). We used AGI's EarthImager 3D (AGI, 2007b) inversion software to create a model of the 3D survey data.

\section{Resistivity Results}

Line 5

The final inversion result for Line 5 is shown in figure 4, along with the results for Lines 1 and 2 for comparison. The Line 5 model shows a resistivity structure similar to that observed for Lines 1 and 2. Above approximately 2-m depth, conductive features on Line 1 at $205 \mathrm{~m}$ and Line 5 at $182 \mathrm{~m}$ correlate with the position where these transects cross a fenced-in line of inactive high-voltage cables lying on the surface. All three models reveal a very resistive surface layer ( 2 to $4 \mathrm{~m}$ thick) with a westto-east transition in the underlying deposits, from strongly conductive to more resistive, that generally corresponds with the position of the surface scarp. Line 5 appears to show a transition zone between the 
relatively wide, conductive fault zone of Line 1 to the south and the more compact, conductive deformed area of the fault zone of Line 2 to the north. The eastern edges of all profiles exhibit an increasingly resistive character, especially Line 1 east of $200 \mathrm{~m}$, which we interpret to be a more highly disrupted zone related to the crater located just east of these transects. Figure 5 shows these three profiles plotted in 3D space to better view their spatial relationship.
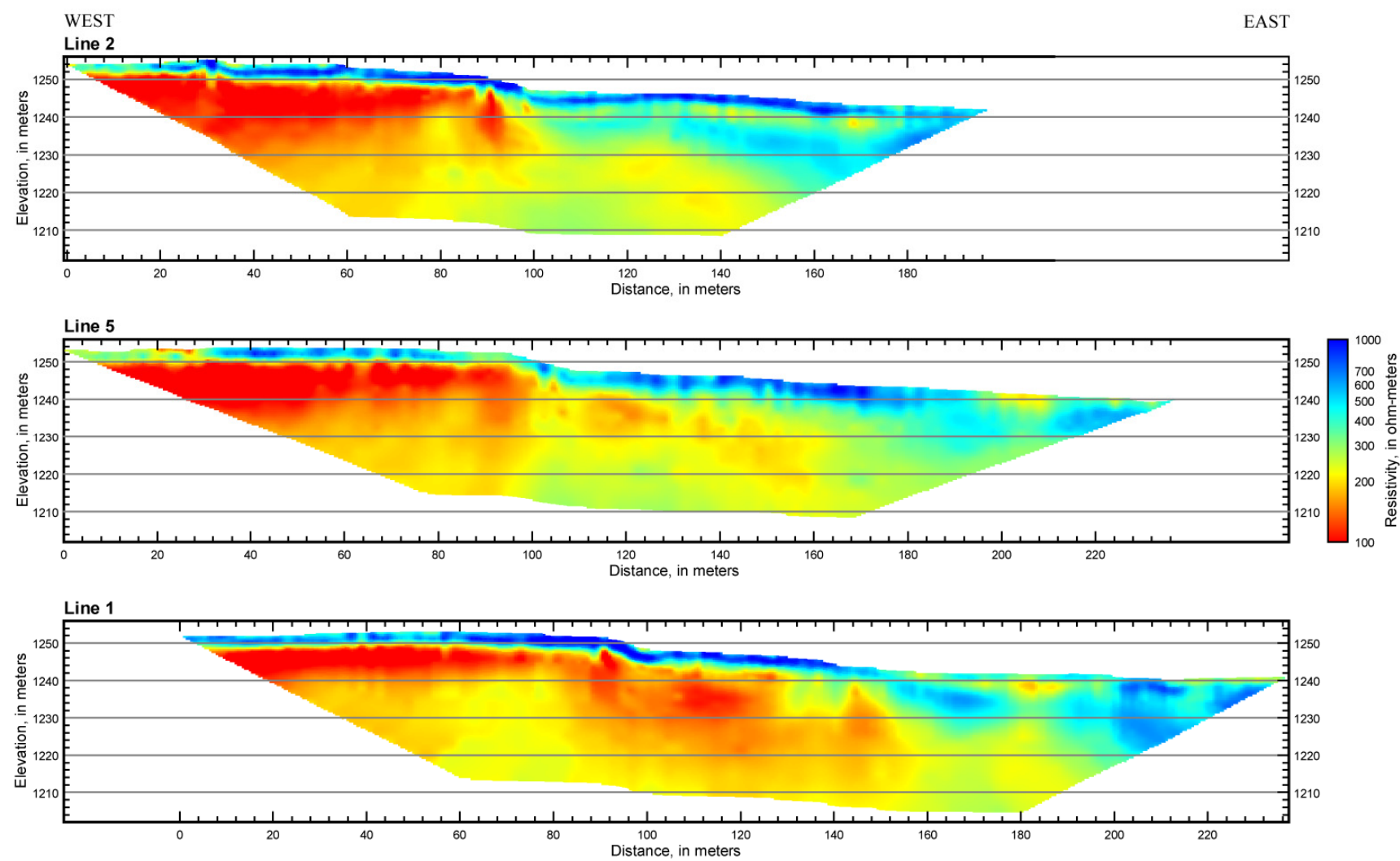

Figure 4. The three DC resistivity profiles acquired across the Yucca Fault in Area 7 in 2006 and 2007 . Vertical exaggeration is approximately 1.2:1. 


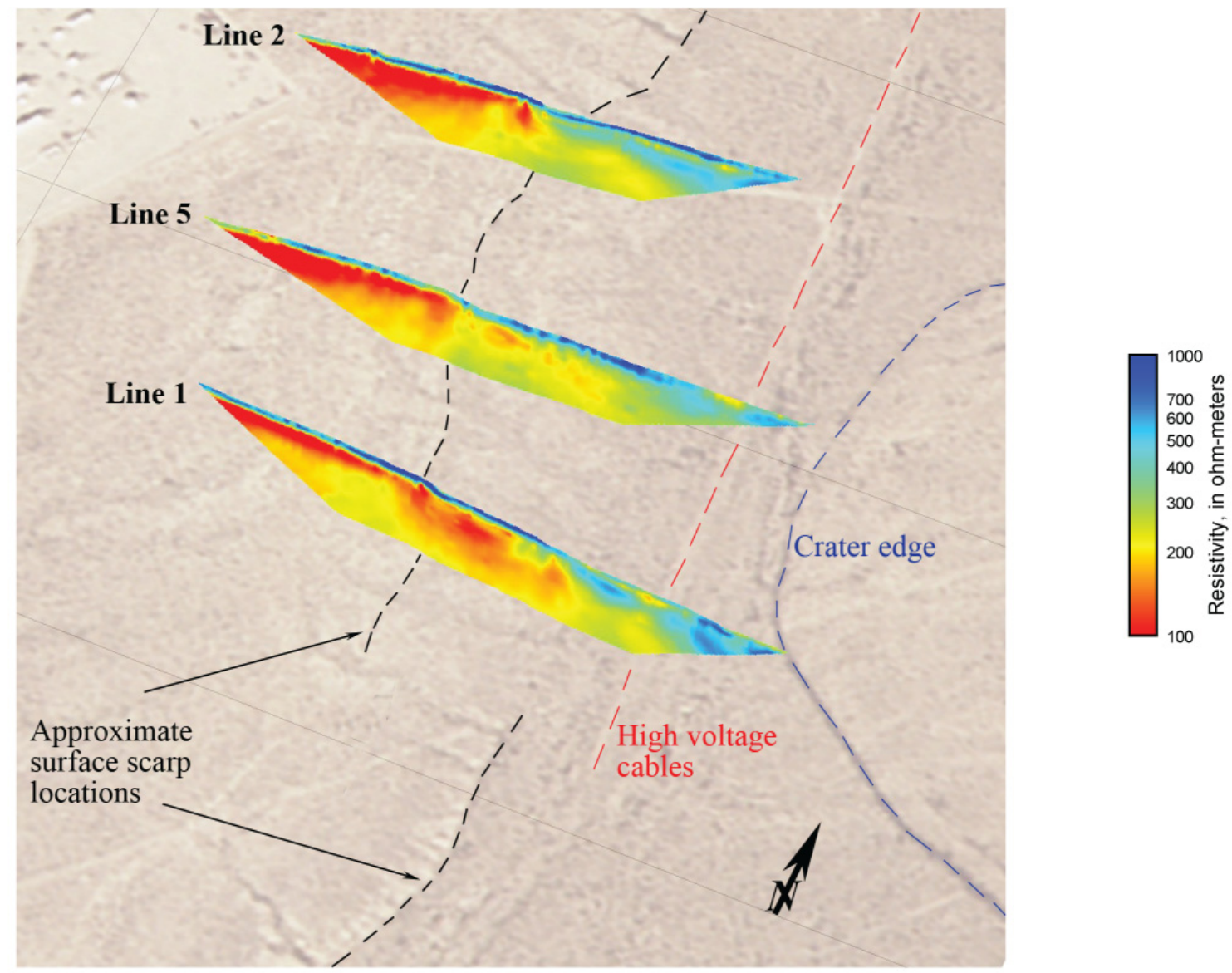

Figure 5. Oblique view of the three DC resistivity profiles acquired across the Yucca Fault in Area 7 in 2006 and 2007 with the aerial photograph underlain. The approximate surface scarp locations are based on the topography along the resistivity transects and features observed in the aerial photograph.

\section{D Survey}

The 3D model (fig. 6) correlates well with the Line 5 2D model, but has an effective depth of penetration of $15 \mathrm{~m}$ as compared with $40 \mathrm{~m}$ for the $2 \mathrm{D}$ models (fig. 4). There is a distinct transition from the more conductive footwall on the west side to the more resistive hanging wall on the east, as represented by the $215-\mathrm{ohm}-\mathrm{m}$ isosurface plotted in figure $6 \mathrm{~d}$. We chose $215 \mathrm{ohms}$ for the isosurface because this represents a transitional value between the two sides of the fault. The isosurface suggests that the fault steps $6-9 \mathrm{~m}$ to the west along its trace between the positions of Lines 1 (to the south) and 
2 (to the north); this is also indicated by the fault scarp at the surface. The small rise in the isosurface to the east of the fault plane likely corresponds with the lower resistivity body centered at about $120 \mathrm{~m}$ on Line 5. The main difference in the resistivity structure shown in the $3 \mathrm{D}$ model as compared to the $2 \mathrm{D}$ models is in the very-near surface. The $3 \mathrm{D}$ model shows a less resistive near surface than the $2 \mathrm{D}$ models. The cause for this discrepancy is not certain, but we infer that it is a result of the different arrays used to acquire the 2D and 3D datasets. The broader electrode spacing used for the 3D model cannot provide the same resolution as the narrow spacing used for the $2 \mathrm{D}$ lines, and the change in array type from inverse-Schlumberger to dipole-dipole may have contributed to the observed loss of shallow resolution.
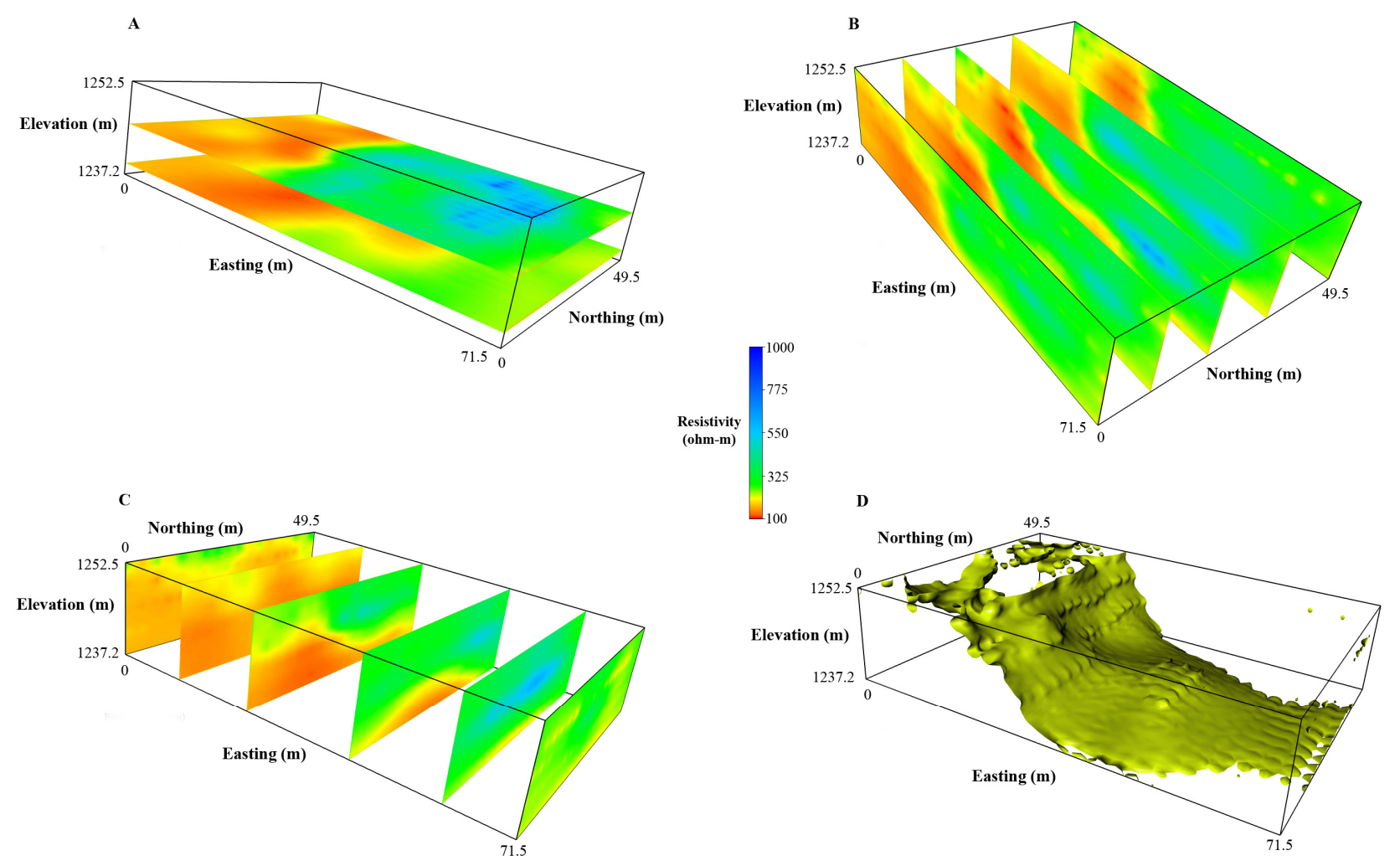

Figure 6. Oblique views of the 3D DC resistivity model: (A) 2 xy slices, (B) $5 \mathrm{xz}$ slices, (C) 6 yz slices, and (D) 215-ohm-m isosurface. We interpret that the steeply dipping part of this surface, at intermediate depths, represents the fault plane. 


\section{Seismic Surveys}

In order to determine mechanical properties of near-surface materials and to assess the impact of fault activity on these properties, we collected P- and S-wave seismic data along three transects that cross mapped faults. Seismic $\mathrm{P}$ waves are sensitive to the compressional and shear properties of materials, and $\mathrm{S}$ waves are sensitive to shear properties. Both wave types can be used for either reflection imaging - using reflected energy to determine the locations of subsurface interfaces - or refraction processing - using the arrival times of refracted energy to determine the subsurface seismic velocity structure.

\section{Data Acquisition and Initial Analysis}

We designed our seismic surveys to facilitate both reflection and refraction processing, although this is generally less viable for P waves than for S waves (for example, Steeples and others, 1997). Following the collection of test data to determine optimal survey parameters, we conducted co-located P- and S-wave surveys along Lines A and B, and a P-wave survey along Line C (fig. 1). For Lines A and B, we deployed 96 geophones (10- and 40-Hz vertical geophones for $\mathrm{P}$ waves and 10-Hz horizontal geophones for $\mathrm{S}$ waves) along the linear transect, and located seismic sources midway between each pair of adjacent geophones and at the two ends of the line for a total of 97 source locations. For Line C, the survey geometry was the same except that we employed 72 geophones and 73 source locations (see table 3). All seismic energy was generated with a sledgehammer. For the P-wave data, we stacked (averaged) data from multiple vertical impacts on a polycarbonate plastic plate. For the S-wave data we used horizontal hammer impacts on the aluminum source described by Haines (2007). Table 3 summarizes the acquisition geometry for the seismic surveys. 
Table 3. Acquisition geometry for seismic surveys.

\begin{tabular}{|cccccc|}
\hline Line & $\begin{array}{c}\text { Total } \\
\text { number of } \\
\text { geophones }\end{array}$ & $\begin{array}{c}\text { Geophone } \\
\text { spacing }\end{array}$ & $\begin{array}{c}\text { Geophone } \\
\text { type }\end{array}$ & $\begin{array}{c}\text { Source } \\
\text { spacing }\end{array}$ & Line length \\
\hline \hline Line A (P wave) & 96 & $3 \mathrm{~m}$ & Vertical & $3 \mathrm{~m}$ & $288 \mathrm{~m}$ \\
Line A (S wave) & 96 & $3 \mathrm{~m}$ & Horizontal & $3 \mathrm{~m}$ & $288 \mathrm{~m}$ \\
Line B (P wave) & 96 & $2 \mathrm{~m}$ & Vertical & $2 \mathrm{~m}$ & $192 \mathrm{~m}$ \\
Line B (S wave) & 96 & $2 \mathrm{~m}$ & Horizontal & $2 \mathrm{~m}$ & $192 \mathrm{~m}$ \\
Line C & 72 & $1 \mathrm{~m}$ & Vertical & $1 \mathrm{~m}$ & $72 \mathrm{~m}$ \\
\hline
\end{tabular}

P-wave data quality is generally quite good, and clear first arrivals are present for most shot/receiver pairs (fig. 7). Curved arrivals may be seen in some shot gathers and sorted commonmidpoint (CMP) gathers, but it is unclear whether these are reflections or diffractions. Regardless of their origin, these arrivals are not widespread in the data, indicating that coherent, laterally extensive reflectors are not present at the site. Due to the lack of definitely interpretable, coherent reflections in the data we do not present processed reflection sections for these data. We suggest that the caliche-rich nature of the surficial alluvial materials results in fast, efficient P-wave propagation and clear first arrivals, but that later-arriving energy is dominated by diffraction and scattering from individual caliche bodies rather than by reflection from coherent interfaces. 

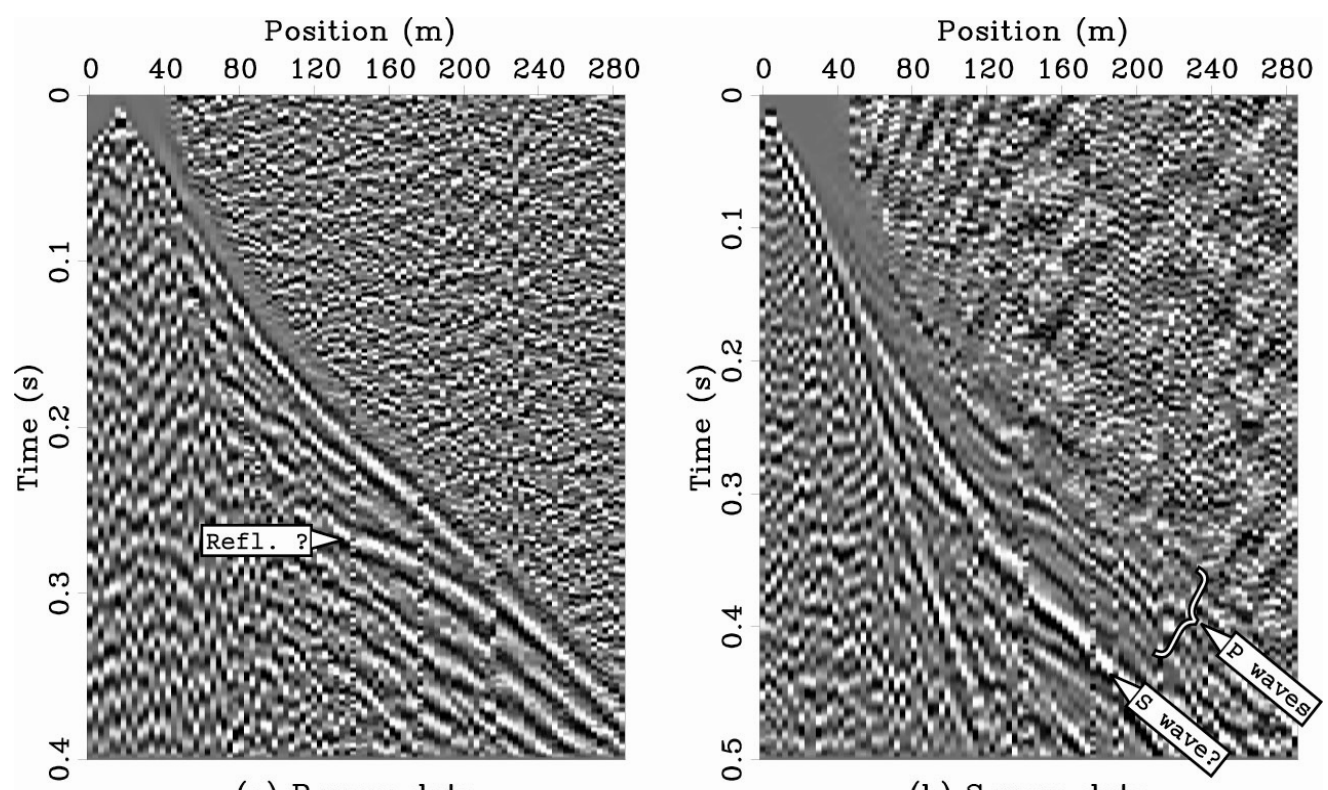

(a) P wave data

(b) S wave data

Figure 7. Seismic shot gathers from Line A. P-wave shot gather (a) shows clear first arrivals at all offsets, and possible reflected or diffracted energy (labeled "refl. ?"). S-wave shot gather (b) shows strong converted P-wave energy that obscures the true S-wave first arrival.

$\mathrm{S}$-wave data quality is generally rather poor, showing strong converted $(\mathrm{P})$ energy in most, or all, stacked shot gathers (fig. 7). As a result, interpreting true S-wave arrivals is difficult or impossible, and the data were not used for further processing. We interpret that the strong conversions are due to the presence of caliche in the shallow subsurface; the resulting jumbled subsurface distribution of partially cemented alluvium provides many small, hard surfaces where the S-wave energy readily scatters and converts to P-waves.

\section{Refraction Modeling}

Models of seismic velocity can be determined along survey transects, and the models extend to a depth determined by the survey parameters and the subsurface velocity structure. These models are generally created using arrival times for particular seismic events, most commonly the arrival time of 
the first seismic energy for each source/receiver pair. We tested two different algorithms for the creation of seismic velocity models from P-wave first arrival times.

Though generally effective in our experience (for example, Powers and others, 2007; Powers and Burton, 2006), the commercial processing package Rayfract (IRI, 2006) failed to produce meaningful results for these Nevada Test Site data despite numerous attempts and various parameter choices. The inversion did not converge on any particular model even when run for as many as 200 iterations, such that no final result could be determined. Intermediate velocity models show low velocities interrupted by an uneven distribution of high-velocity channels that trap seismic energy. Although these models are inconsistent with known geology and cannot be interpreted because the inversions did not converge, they do suggest that the presence of high-velocity caliche in the near surface contributes to the modeling problems. It is unclear whether the algorithm was unsuccessful due to the smoothed-grid nature of the velocity model parameterization, or due to the means by which the program determines a starting model for the inversion.

We also tested velocity modeling using the freely available velocity modeling code "rayinvr" that is described by Zelt and Smith (1992). This algorithm features a velocity model that is defined by distinct boundaries and velocities that are defined at arbitrary points along the boundaries. We employed simple two- and three-layer models to represent the subsurface geology along each transect. We determined 1-dimensional (laterally homogeneous) starting models for each transect through forward modeling of P-wave first arrival times and then sequentially inverted for laterally heterogeneous velocities for each layer from the top down. We parameterized the models sparsely, so as to capture the essential elements of the data without danger of over-fitting data or overparameterizing the models. The result is a minimum-structure model for each transect, with only those model features that are required by the data. We iterated to convergence, stopping when the change between iterations was negligible and/or unnatural. We used only a subset of the collected data 
(approximately every fourth shot) with this algorithm due to ray-tracing problems encountered with larger numbers of shots.

Velocity models determined for a given dataset are non-unique; that is, many different models will fit the data to some degree. Inversion (as opposed to forward-modeled) results have the advantage that they represent the model that best fits the data according to a chosen quantitative measure, and with less chance of over-fitting the data (for example, Zelt, 1999; Tarantola, 2005). As described by Zelt (1999), the fit of a particular model to seismic arrival time data may be quantitatively judged on the basis of the root-mean-squared (RMS) travel time residual and the normalized chi-squared travel time misfit. The RMS is the square root of the mean of the squares of the individual travel time residuals (difference between predicted and observed arrival times); as such, a value of zero is desirable but is, of course, unlikely to be achieved. The chi-squared misfit is a different statistical measure; a value of 1 is desirable and values close to 1 are considered adequate (Zelt, 1999). For each of our velocity models, we provide these quantitative measures of fit, and in Appendix B we provide plots of measured and predicted arrival times for qualitative assessment.

\section{P-Wave Velocity Models}

\section{Line A}

Seismic Line A is nearly coincident with DC resistivity Line 2 (fig. 2). The velocity model (fig. 8) shows a pronounced low velocity zone at the surface position of the Yucca Fault, extending to the base of the model. Also, at the eastern end of the model, a second low velocity zone may be seen. This likely corresponds with deformation associated with the crater located just east of the survey area. This velocity model fits 1,374 observed first arrival times, with an RMS travel time residual of $3.350 \mathrm{~ms}$, and a normalized chi-squared value of 1.797 . 


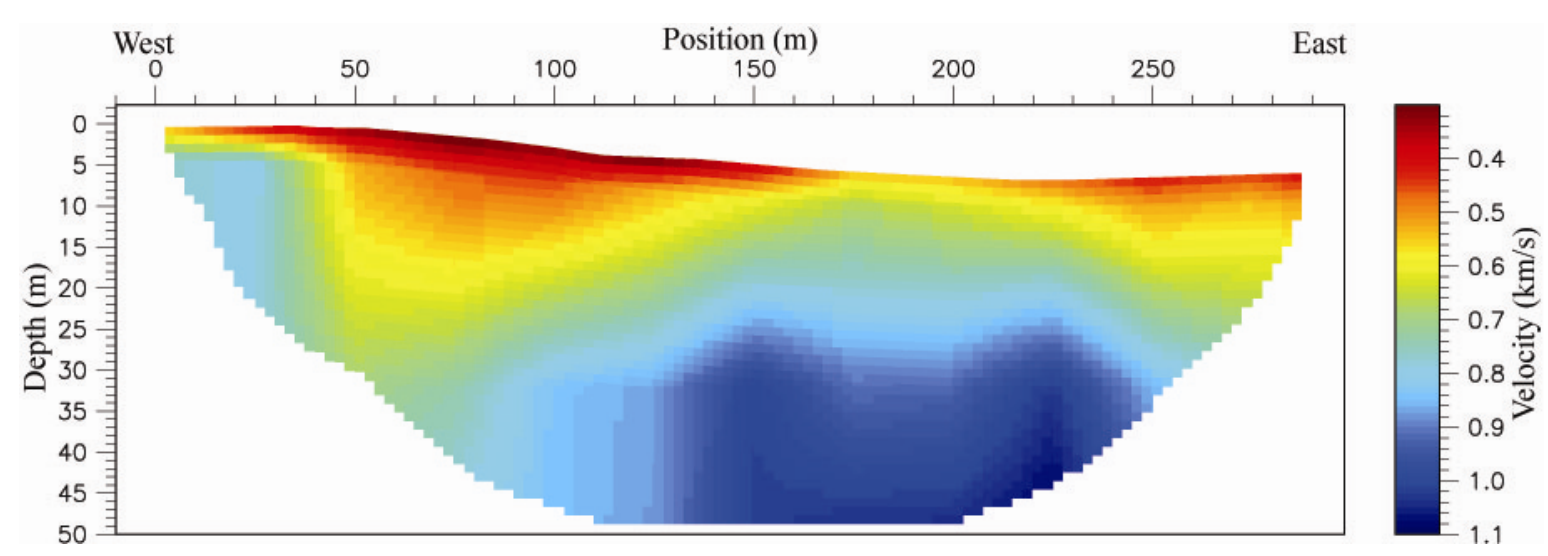

Figure 8. P-wave refraction velocity model for Line A. Vertical exaggeration is 2:1. Present-day Yucca Fault scarp is located between positions 75 and $125 \mathrm{~m}$.

Line B

Seismic Line B is coincident with 2006 DC resistivity Line 3 (fig. 3). The velocity model (fig. 9) is more laterally homogeneous and shows generally lower velocities than the model for Line A. Lateral variation may be observed, similar to that observed in the DC resistivity results (Asch and others, 2008). Many small faults and surface cracks have been mapped in the area of this transect, and their presence may be related to the observed patterns. This velocity model fits 1,523 first arrival times, with a RMS travel time residual of $2.892 \mathrm{~ms}$ and a normalized chi-squared value of 1.339 .

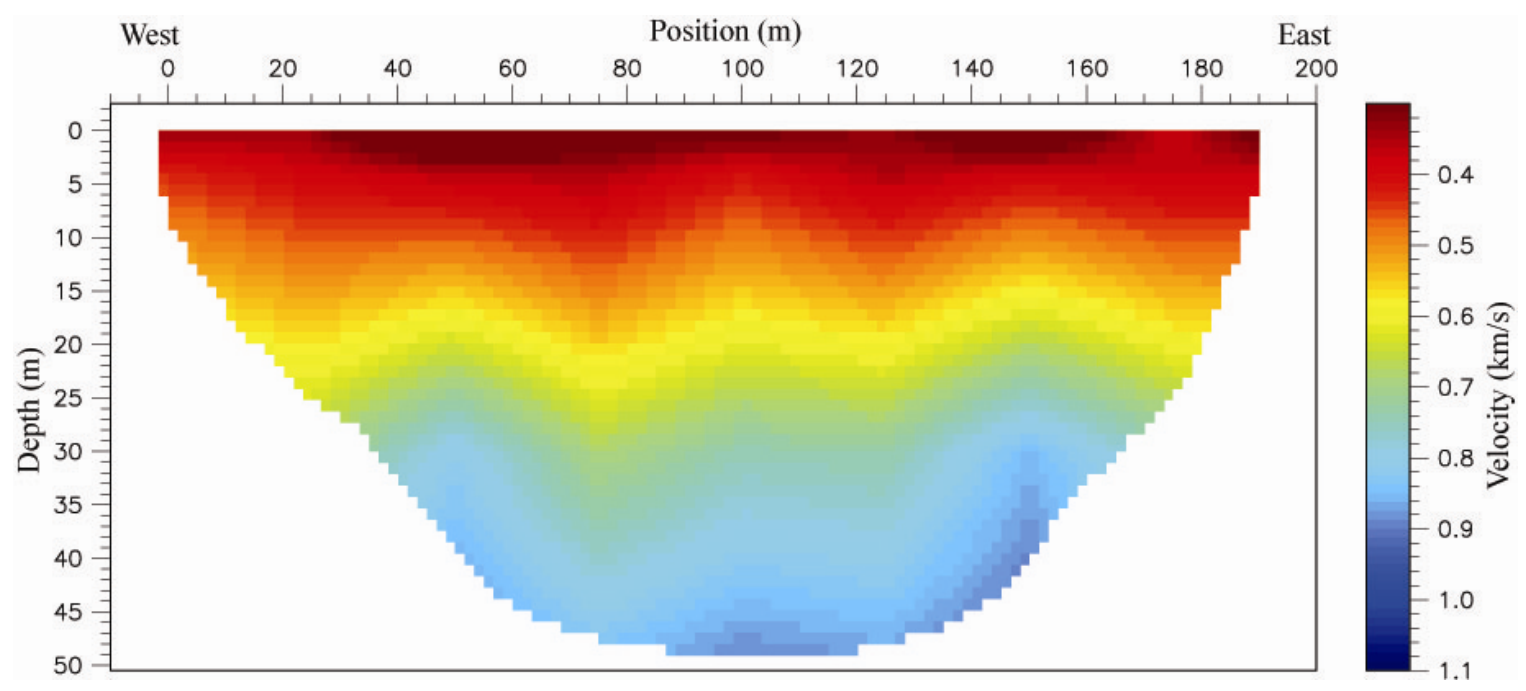

Figure 9. P-wave refraction velocity model for Line B. Vertical exaggeration is 2:1. 
Line C

Seismic Line C is coincident with, although shorter than, 2006 DC resistivity Line 4 (fig. 3). Because the line is shorter (and thus the maximum source-receiver offsets smaller) than the other lines, the depth of penetration is considerably shallower than the other seismic surveys. The inversion process was not entirely successful for this model, requiring manual interaction between each iteration to avoid inconsistent results. The velocity model (fig. 10) is generally homogeneous and shows higher velocities than the other models. However, a minor low velocity zone exists near the center of the transect, corresponding approximately with the location of a small fault identified in an adjacent trench. Note that the color scale is different for Figure $10 \mathrm{~b}$ than for the previous velocity models; without the exaggerated scale the model appears mostly homogenenous (fig. 10a). Whether the fault is responsible for the observed low velocity zone is uncertain; both the fault and the velocity anomaly are very minor and their collocation may be purely coincidental. The velocity model fits 1,221 first arrival times, with a RMS travel time residual of $1.478 \mathrm{~ms}$ and a normalized chi-squared value of 2.187. 


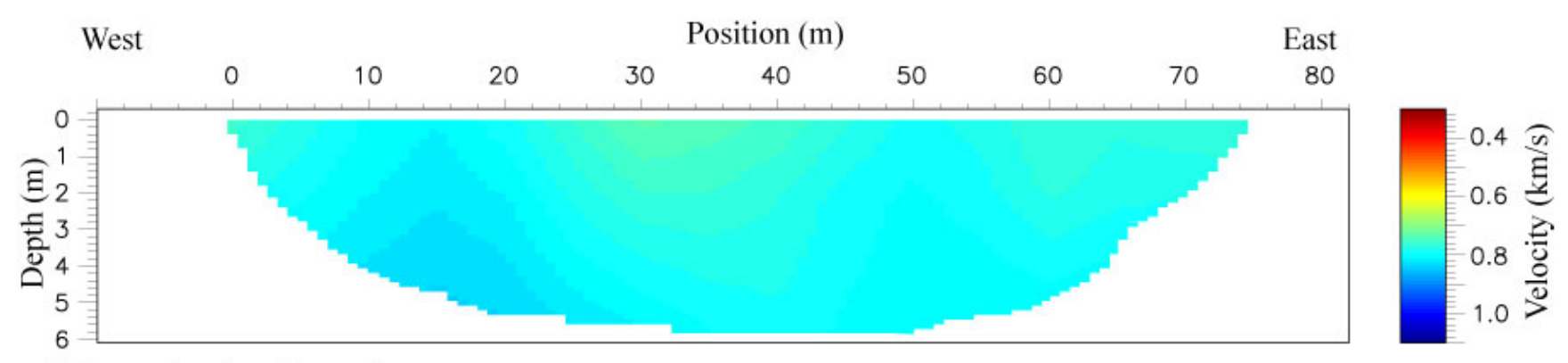

(a) Same color scale as figs.7 and 8.

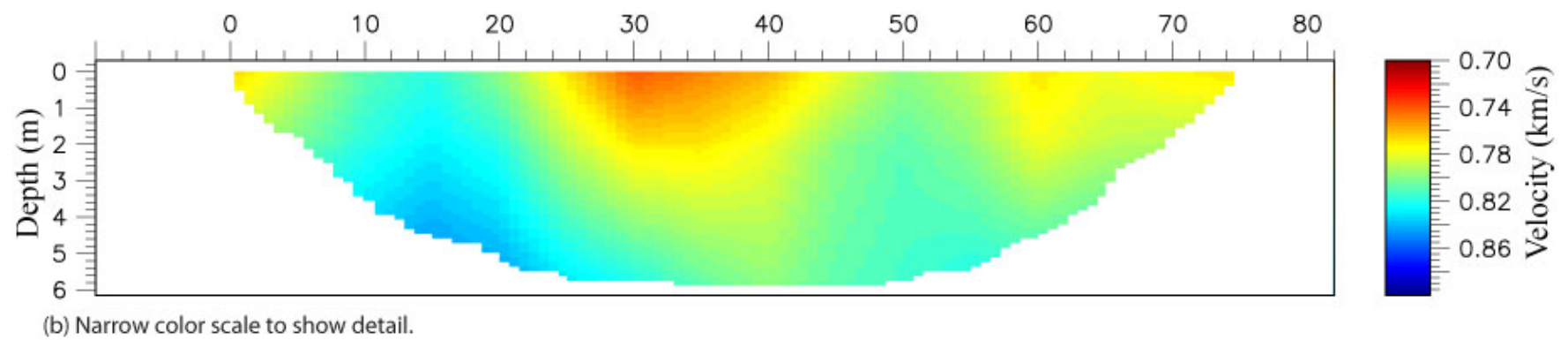

Figure 10. P-wave refraction velocity model for Line $C$. Vertical exaggeration is $2: 1$. The model is plotted with the same color scale as the other velocity models (a) and with a different velocity color scale (b) in order to better show the small-scale velocity heterogeneity along this transect.

\section{Discussion and Conclusions}

Although the DC resistivity results from Lines 1,2, and 5 show distinct changes in electrical properties across the Yucca Fault, the origin of these contrasts is not obvious. High conductivity can be due to the presence of clay minerals or solids (particularly salt) dissolved in the pore fluid (and thus can be an indication of pore water itself). Caliche likely impacts the conductivity of alluvium, although uncertainty exists regarding whether caliche causes higher or lower conductivity. Laboratory tests of similar alluvium from a different location showed conductivity increasing with caliche content (Olhoeft and Capron, 1993). Along resistivity Lines 1, 2, and 5 (fig. 4), we see a highly conductive layer on the west side of the Yucca Fault that does not extend to the east side of the fault. The conductive layer could be caliche and/or salt that are regionally uniform but disrupted to the east of the fault, or the pattern could indicate preferential accumulation of caliche/salt to the west of the fault. 
The presence of a seismic P-wave low velocity zone at the location of the Yucca Fault is unsurprising, and almost certainly corresponds with an area of deformation related to the fault. However, the low velocity zone extends as much as $50 \mathrm{~m}$ west of the fault scarp and the mapped surface fractures related to recent activity on the fault, and surface cracks have been mapped west of the fault scarp. Also, to the north of Lines 2 and A, a splay of the Yucca Fault is mapped to the west of the splay that corresponds with the fault scarp on Lines 2 and A (the northern splay is shown in yellow in figure 1). Although the northern splay is not mapped as far south as our survey lines, the surface cracks and the subsurface low velocity zone suggest that the zone of past and current activity on the Yucca Fault extends west of the current scarp.

The generalized schematics shown in figure 11 illustrate one scenario that could result in the physical properties observed at the Yucca Fault. With the ground surface on the east side of the fault downdropping, sediment deposition rates there must be greater than on the west side of the fault in order to maintain the minimal surface scarp above the 200 to $400 \mathrm{~m}$ of bedrock offset. Thus, the gradual accumulation of salts and caliche that occurs at a uniform rate throughout the area (due to upward migration of dissolved materials and evaporation) will lead to greater concentrations of these materials on the west side of the fault where sedimentation rates are slower. This would result in the observed high conductivity on the west side of the study area.

The total field magnetic anomaly noted by Asch and others (2008) may be explained with a similar mechanism. Given the abundance of volcanic materials in the area, it is reasonable to assume that some of the alluvial fan deposits in the study area contain a large amount of volcanic (and highly magnetic) material. If a particular layer of deposits was highly magnetic, and then was buried by subsequent deposits that were not as magnetic, we would expect to see the observed magnetic pattern (high measurements on the footwall side of the fault, and low values on the hanging-wall side of the fault). 


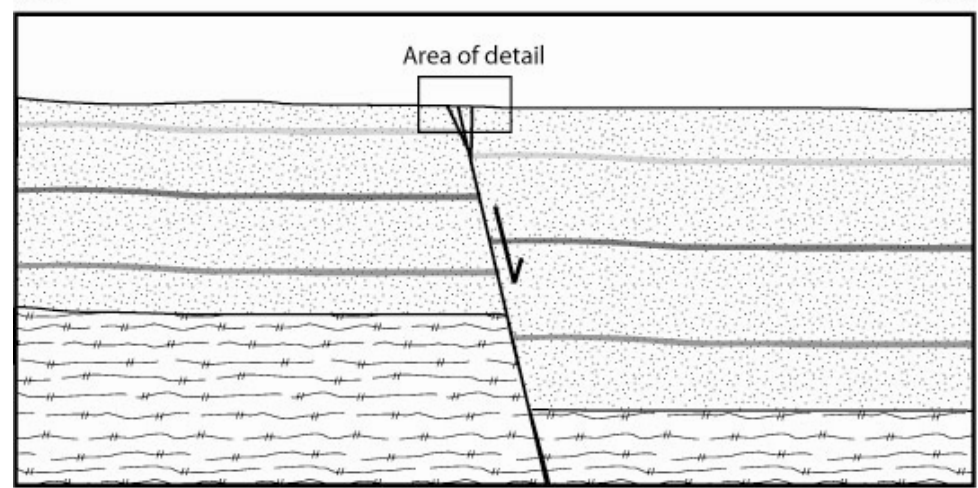

(a) Basin scale.

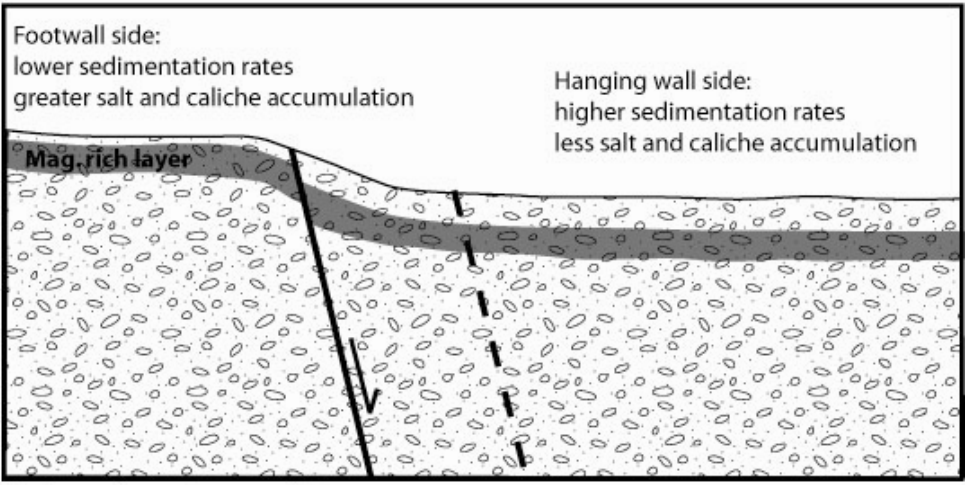

(b) Site scale: previous conditions.

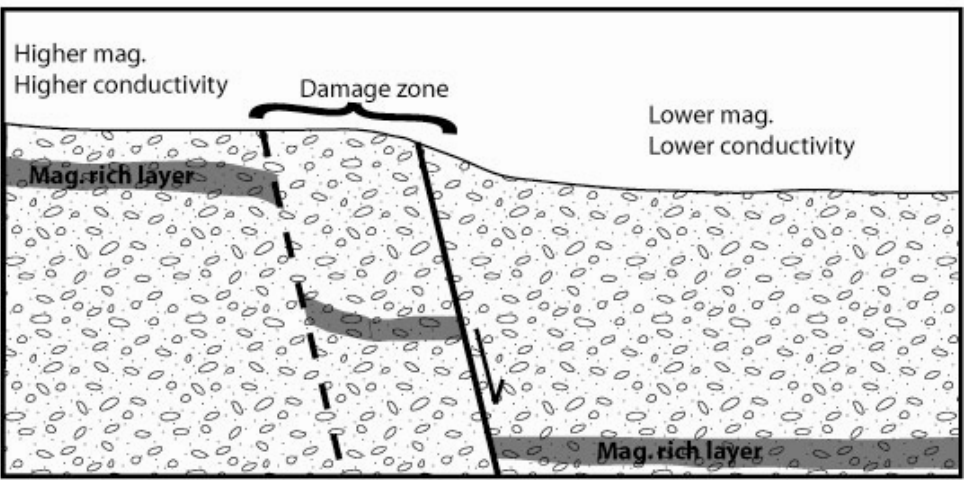

(c) Site scale: present day conditions.

Figure 11. Generalized schematics illustrating one possible sequence of events that would produce the pattern of physical properties observed in the area of DC resistivity Lines 1, 2, and 5, and seismic Line A. At the basin scale (a), we see that the hangingwall (east) side of the fault has dropped several hundred meters while sedimentation has maintained an approximately smooth ground surface, requiring more rapid sediment deposition on the east side of the fault than on the west. At the site scale (b and c), we see the meter-scale fault scarp and note that enhanced sedimentation rates on the east side of the fault will tend to preferentially bury deposited layers. Lateral fault migration creates the broad damage zone indicated by the seismic data, and preferential deposition creates the conductivity and magnetic patterns observed in those datasets. 
Models of the resistivity Lines 1,2, and 5 and seismic Line A show a distinct character at the east end of each line. The resistivity models show decreased resistivity at the east ends, and the seismic models show decreased P-wave velocity. We interpret that this pattern is unrelated to Yucca Fault but is due to deformation related to the test crater just east of our survey lines (the circular surface cracks shown in figure 2 show the margins of this crater). Cracks extending into the subsurface would tend to reduce the P-wave velocity and would act as preferential flow paths for precipitation, leading to the dissolution and dissemination of accumulated salt and caliche.

Interpretation of the resistivity and seismic data along the other transects is more challenging. We note that the character of the P-wave velocity model for Line B is similar to the 2006 DC resistivity model for Line 3 (Asch and others, 2008), and interpret that the same mechanisms are likely responsible for this similarity. Mechanical deformation in the shallow subsurface, associated with the mapped surface cracks, may be directly responsible for the resistivity and seismic velocity heterogeneity. Cracks would likely have lower seismic velocity than the surrounding material, and they could (particularly when fresh) act as conduits for preferential water flow, flushing away accumulated salts. Alternatively, the observed pattern may indicate minor water saturation differences that would also result in resistivity and seismic velocity heterogeneity. These saturation differences could be due to a heterogeneous sediment grain size distribution.

The P-wave velocity model for Line C (fig. 10) shows minor heterogeneity near a minor fault identified in a nearby pit. However, given the low amplitude of the velocity anomaly and the very minor nature of the mapped fault, we are hesitant to draw any firm conclusions regarding their association.

Borehole information, with detail in the depth range of our surveys, would help constrain our interpretations of these data. Additional geophysical surveys (P-wave seismic, DC resistivity, and magnetic), particularly in areas that are not as near to test craters as our Area 7 surveys, would provide 
an improved understanding of the regional extent of the characteristics that we observe in Area 7. Such surveys would help to show whether these characteristics are solely due to the fault or whether they are also related to the nearby crater or other features. Additionally, such surveys would provide a better understanding of the properties of site material in the absence of faulting.

\section{Acknowledgments}

We are grateful to Chuck Lindsay for his enthusiastic and essential assistance with data collection. We thank Mike Powers and Jeff Lucius for insightful comments on all aspects of this manuscript.

\section{References Cited}

AGI (Advanced Geosciences, Inc.), 2007a, Instruction Manual for EarthImager 2D Version 2.2.0

Resistivity and IP Inversion Software: Austin, Texas, Advanced Geosciences Inc., 134 p.

AGI (Advanced Geosciences, Inc.), 2007b, Instruction Manual for EarthImager 3D Version 1.3.9 Resistivity Inversion Software: Austin, Texas, Advanced Geosciences Inc., 89 p.

Asch, T.H., Rodriguez, B.D., Sampson, J.A., Wallin, E.L., and Williams, J.M., 2006, Deep resistivity structure of Yucca Flat, Nevada Test Site, Nevada: U.S. Geological Survey Open-File Report 2006-1261, 86 p.

Asch T.H., Sweetkind, D.S., Burton, B.L., and Wallin, E.L., 2008, Detailed geophysical fault characterization in Yucca Flat, Nevada Test Site, Nevada: U.S. Geological Survey Open-File Report 2008-1346. 
Barosh, P.J., 1968, Relationships of explosion-produced fracture patterns to geologic structure in Yucca Flat, Nevada Test Site, in Eckel, E.B., ed., Nevada Test Site, Geological Society of America Memoir 110, p. 199-217.

Grasso, D.N., 2001, GIS surface effects archive of underground nuclear detonations conducted at Yucca Flat and Pahute Mesa, Nevada Test Site, Nevada: U.S. Geological Survey Open-File Report 2001-0272, 34 p., 1 plate, 1 CD-ROM.

Haines, S.S., 2007, A hammer-impact, aluminum, shear-wave seismic source: U.S. Geological Survey Open-File Report 2007-1406, 5 p.

IRI (Intelligent Resources, Inc.), 2006, Rayfract manual - tutorial: Vancouver, B.C., Canada, Intelligent Resources, Inc., 18 p., accessed August 27, 2007, at http://www.rayfract.com/.

Olhoeft, G.R., and Capron, D.E., 1993, Laboratory measurements of the radiofrequency electrical and magnetic properties of soils from near Yuma, Arizona: U.S. Geological Survey Open-File Report 93-701, $214 \mathrm{p}$.

Phelps, G.A., and McKee, E.H., 1999, High-angle faults in the basement of Yucca Flat, Nevada Test Site, Nevada, based on analysis of a constrained gravity inversion surface: U.S. Geological Survey Open-File Report 99-383, 11 p.

Powers, M.H., and Burton, B.L., 2006, Questa baseline and pre-mining ground-water quality investigation. 24. Seismic refraction tomography for volume analysis of saturated alluvium in the Straight 
Creek drainage and its confluence with Red River, Taos County, New Mexico: U.S. Geological Survey Scientific Investigations Report 2006-5166, 19 p.

Powers, M.H., Haines, S.S., and Burton, B.L., 2007, Compressional and shear wave seismic refraction tomography at Success Dam, Porterville, California, in Gamey, Jeff, ed., Proceedings of the Symposium on the Application of Geophysics to Engineering and Environmental Problems, April 1-5, 2007, Denver, CO, 10 p.

Reynolds, J.M., 1997, An Introduction to applied and environmental geophysics: Chichester, England, John Wiley \& Sons, 796 p.

Rubin, Y. and Hubbard, S.S., eds., 2006, Hydrogeophysics, water science and technology library, v. 50: Dordrecht, The Netherlands, Springer, 523 p.

Slate, J.L., Berry, M.E., Rowley, P.D., Fridrich, C.J., Morgan, K.S., Workman, J.B., Young, O.D., Dixon, G.L., Williams, V.S., McKee, E.H., Ponce, D.A., Hildenbrand, T.G., Swadley, W C, Lundstrom, S.C., Ekren, E.B., Warren, R.G., Cole, J.C., Fleck, R.J., Lanphere, M.A., Sawyer, D.A., Minor, S.A., Grunwald, D.J., Laczniak, R.J., Menges, C.M., Yount, J.C., and Jayko, A.S., 2000, Digital geologic map of the Nevada Test Site and vicinity, Nye, Lincoln, and Clark Counties, Nevada, and Inyo County, California: U.S. Geological Survey Open-File Report 99-554A, 53 p., scale 1:120,000; at http://pubs.usgs.gov/of/1999/ofr-99-0554/.

Steeples, D.W., Green, A.G., McEvilly, T.V., Miller, R.D., Doll, W.E., Rector, J.W., 1997, A workshop examination of shallow seismic reflection surveying: The Leading Edge, v. 16, p. 1641-1647. 
Sumner, J.S., 1976, Principles of induced polarization for geophysical exploration: Amsterdam, The Netherlands, Elsevier Scientific Publishing Company, 277 p.

Tarantola, A., 2005, Inverse problem theory: Philadelphia, Society for Industrial and Applied Mathematics, $342 \mathrm{p}$.

Winograd, I.J., and Thordarson, William, 1975, Hydrogeologic and hydrochemical framework, southcentral Great Basin, Nevada-California, with special reference to the Nevada Test Site: U.S. Geological Survey Professional Paper 712-C, 126 p.

Zelt, C.A., 1999, Modelling strategies and model assessment for wide-angle seismic traveltime data: Geophysical Journal International, v. 139, p. 183-204.

Zelt, C.A., and Smith, R B., 1992, Seismic travel time inversion for 2-D crustal velocity structure: Geophysical Journal International, v. 108, p. 16-34.

Zohdy, A.A.R., Eaton, G.P., and Mabey, D.R., 1974, Application of surface geophysics to ground-water investigations: U.S. Geological Survey Techniques of Water-Resources Investigations, Book 2, Chapter D1, $123 \mathrm{p}$. 


\section{Appendix A}

Resistivity profiles may be assessed by comparing the measured apparent resistivity values (essentially "raw data") with those predicted by the inverse model. Figures A-1, A-2, and A-3 show the measured and calculated (forward modeled) apparent resistivity pseudosections for Lines 1, 2, and 5, along with the inverted resistivity profile. The measured and calculated apparent resistivity

pseudosections are very similar, in fact nearly indistinguishable, implying a good fit of the model to the data. 

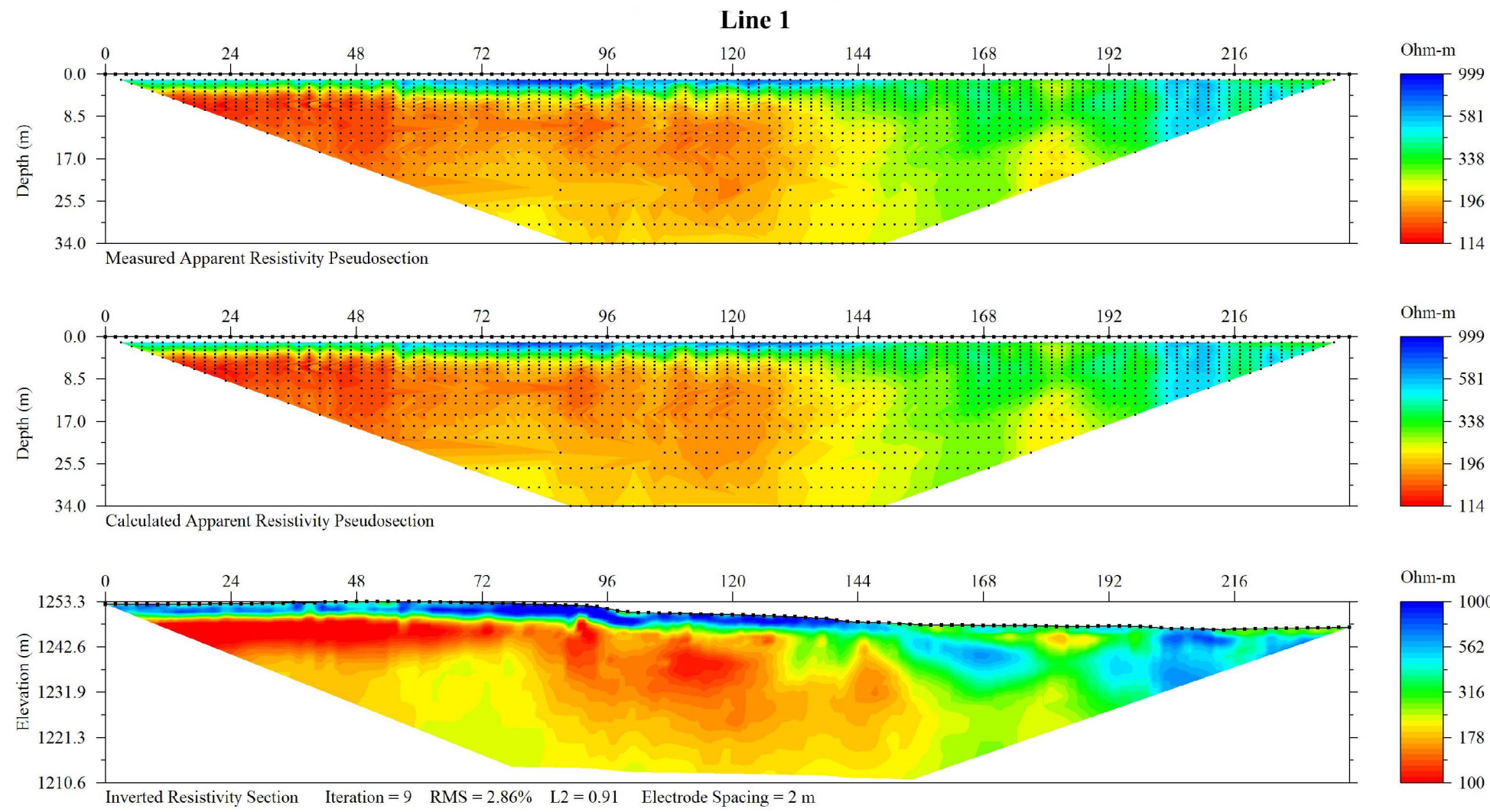

Figure A-1. For Line 1: inverted inverse Schlumberger DC resistivity profile (bottom image) with raw data (top image) and forward modeled (middle image) pseudosections. All sections are plotted from west to east. The black dots in the two pseudosections represent the pseudosection data points that were included in creating the final inverted section. 

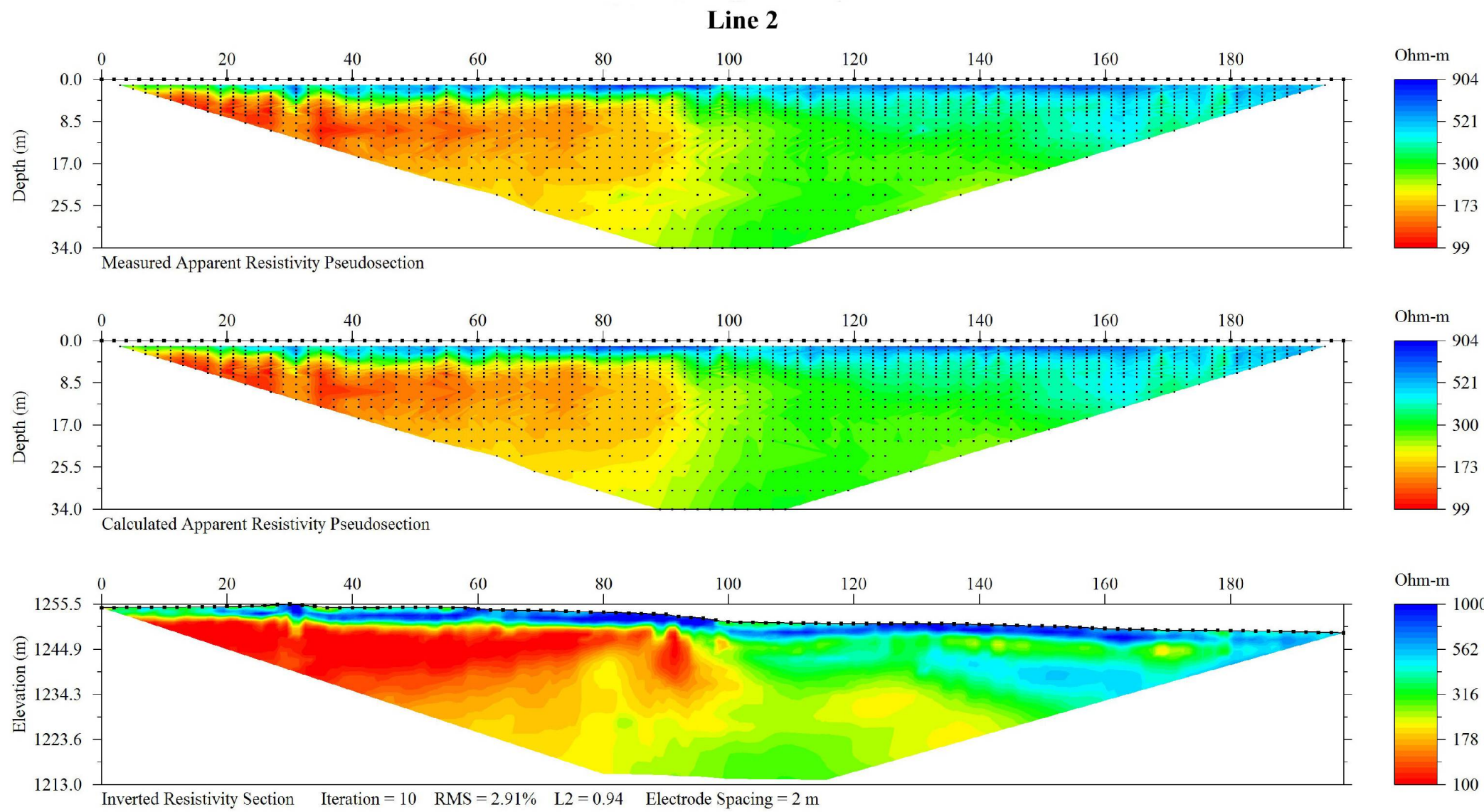

Figure A-2. For Line 2: inverted inverse Schlumberger DC resistivity profile (bottom image) with raw data (top image) and forward modeled (middle image) pseudosections. All sections are plotted from west to east. The black dots in the two pseudosections represent the pseudosection data points that were included in creating the final inverted section. 

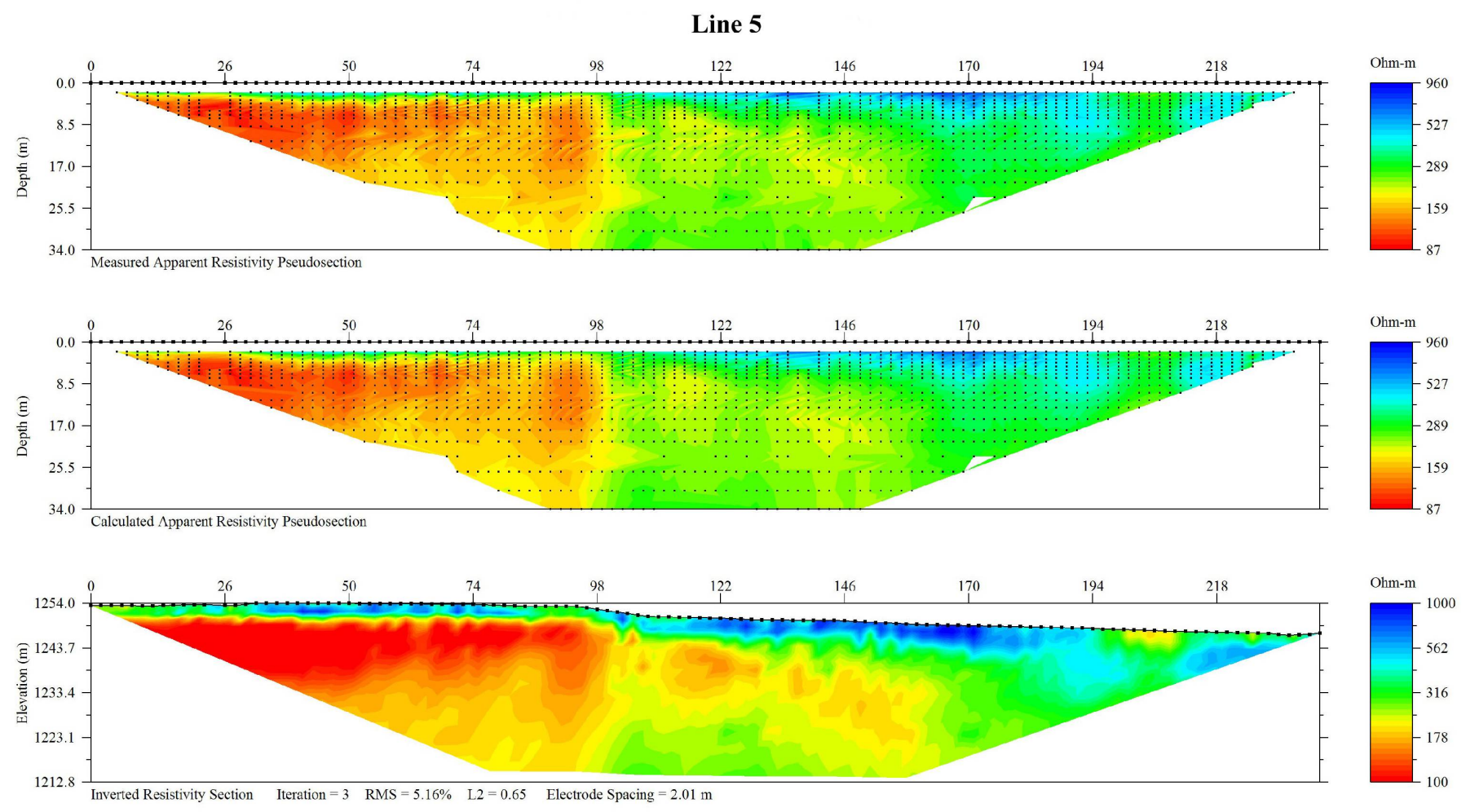

Figure A-3. For Line 5: inverted inverse Schlumberger DC resistivity profile (bottom image) with raw data (top image) and forward modeled (middle image) pseudosections. All sections are plotted from west to east. The black dots in the two pseudosections represent the pseudosection data points that were included in creating the final inverted section. 


\section{Appendix B}

Seismic velocity models may be qualitatively assessed by comparing measured and predicted arrival times. Here, we provide plots of these arrival times for each seismic survey line. The general trends of the measured arrival times are matched by the model-predicted arrivals, and fit is quite good in most parts of the models. Particularly for Line A, some arrivals are not predicted at all; this is an unfortunate result of modeling problems associated with sharp velocity contrasts and inversions. Ray coverage is good overall for these models and, having explored the model space, we are confident that the presented models are indeed appropriate and accurate. 

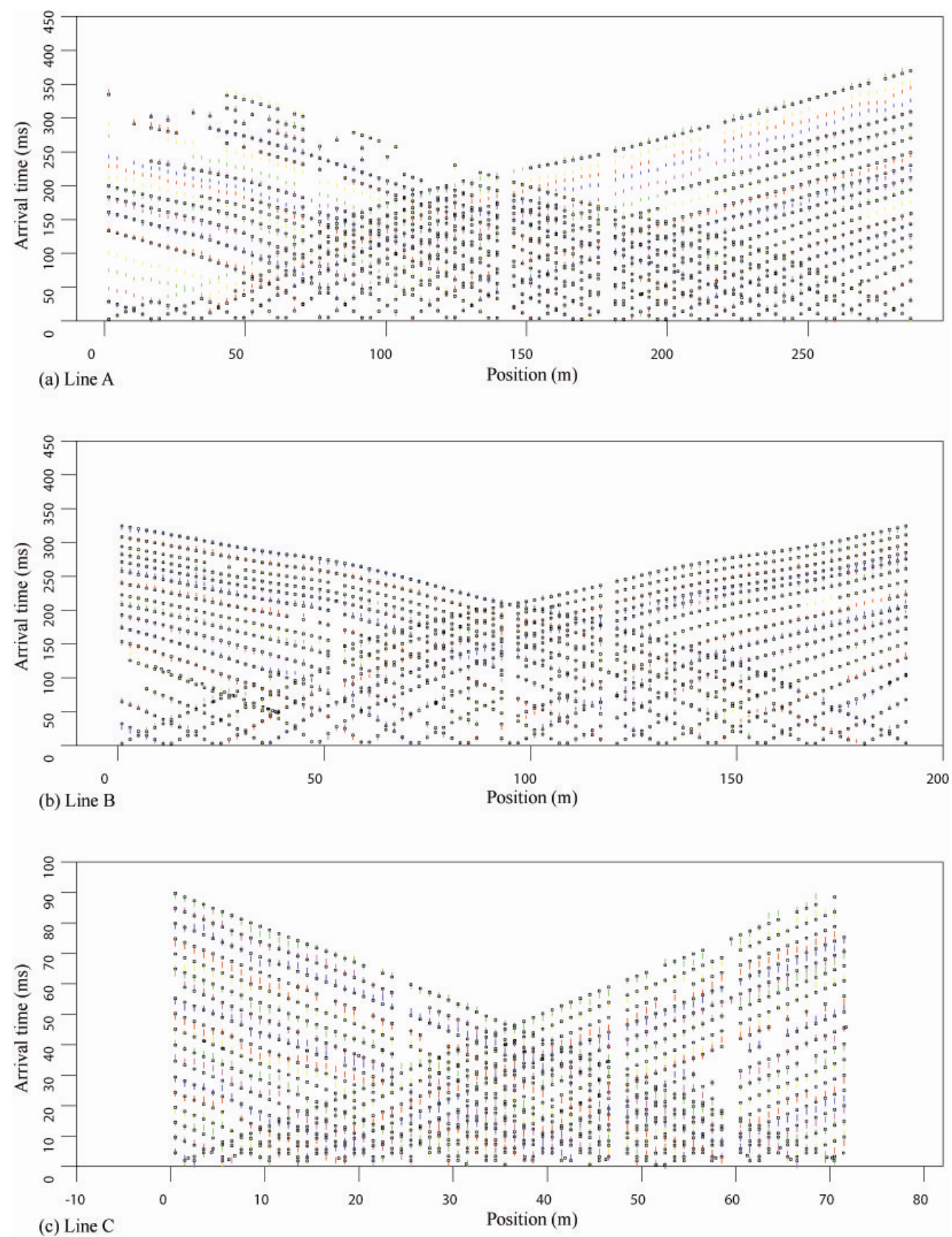

Figure B-1. Arrival time plots for each seismic line showing model-predicted arrival times as small black circles and measured arrival times as colored symbols whose height represents an estimate of pick error. Note that the horizontal and vertical scales are different for the three plots. 